\title{
Processo integrado de projeto, aquisição e execução de sistemas de impermeabilização em edifícios residenciais
}

\author{
Evaluation of the integrated process for the design, \\ aquisition, and execution of waterproofing systems in \\ residential buildings
}

\begin{abstract}
Jorge Luiz de Aquino Lima
Francisco Uchoa Passos

Dayana Bastos Costa

\section{Resumo}

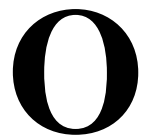

sistema de impermeabilização nos edifícios residenciais passou a ser objeto de preocupação de muitas empresas construtoras, em função dos reparos em obras, que, com freqüência, resultam em danos a outros componentes. Grande parte deste problema está associado à gestão inadequada deste processo desde o projeto até a sua aplicação. O presente artigo tem como objetivo principal sistematizar o processo de identificação de problemas relacionados à gestão de projeto, aquisição e execução do sistema de impermeabilização, a partir de uma estrutura de análise com foco no fluxo de informação, no desperdício e no atendimento às normas em vigor. A pesquisa foi baseada em 16 entrevistas com projetistas de sistemas de impermeabilização, e representantes de empresas construtoras e de sub-contratadas de impermeabilização, análise de documentos, e oito visitas a obras. Os resultados mostraram a necessidade de uma maior integração entre os participantes do processo de impermeabilização, com foco na capacitação, transparência dos processos e controle da produção. As principais contribuições do presente trabalho referem-se à concepção de uma estrutura para sistematização dos problemas na execução de sistemas de impermeabilização, e as recomendações para melhoria da gestão deste processo, visando a atender aos requisitos normativos e reduzir perdas.

Palavras-chave: Impermeabilização. Perdas. Fluxo de informações.

Jorge Luiz de Aquino Lima Faculdade de Tecnologia Senai/Cimatec/Viapol Salvador - BA - Brasil

Francisco Uchoa Passos Faculdade de Tecnologia Senai/Cimatec Salvador - BA - Brasil

Dayana Bastos Costa Universidade Federal da Bahia Salvador - BA - Brasil

Recebido em 15/04/13 Aceito em 10/09/13

\section{Abstract}

The waterproofing system in residential buildings is a major concern for many construction companies, due to the large number of repair works, which often result in damage to other building components. This problem is closely related to flaws in process management from the design phase to site installation. This paper aims to systematize the process of identifying problems related to the design, acquisition and application of waterproofing systems, based on an analytical structure focused on information flow, waste and the compliance with existing standards. The investigation was based on 16 interviews with waterproofing system designers, construction managers, and waterproofing subcontractors, document analysis, and 8 construction site visits. The main findings showed the need for better integration between the participants of the waterproofing process, with a focus on training, process transparency, and production control. The main contributions of this paper is the framework that was devised for the analysis of problems related to the execution of waterproofing process, as well as a set of recommendations for managerial improvements concerning this process, with the aim of improving the conformance to standards and reducing waste.

Keywords: Waterproofing. Waste. Iinformation flow.
\end{abstract}




\section{Introdução}

A estabilidade econômica do país, somada ao desenvolvimento tecnológico e normativo dos sistemas construtivos, tem gerado, num ritmo acelerado, um grande volume de obras prediais para atender ao déficit habitacional brasileiro. Esse cenário contribui para que os investimentos no setor da construção passem a ser constantes, ao mesmo tempo em que exige melhor desempenho dos edifícios, maior profissionalização dos gestores na construção civil e modernização do setor.

Para tanto, observa-se a necessidade de introduzir ações inovadoras nas atividades e etapas construtivas dos diversos subsistemas da construção civil, visando selecionar produtos e serviços que promovam o avanço do setor, bem como garantindo o desempenho na construção dos edifícios e o custo adequado deles. No entanto, essas ações não devem ser focadas apenas nas metas de prazo e custo, dando também a devida atenção às questões de qualidade em termos de projeto, processo e produto acabado, assim como evitando os desperdícios

Sob essa ótica, a redução ou mesmo eliminação do desperdício em todas as suas formas (materiais, tempo, estoque, transporte, improviso, entre outros) passa a assumir papel fundamental na melhoria dos processos construtivos. De acordo com Viana, Formoso e Kalsaas (2012), diversos estudos de diferentes países já confirmaram que as perdas representam uma grande parcela dos custos de produção (HWANG et al., 2009; FORMOSO et al., 2002; LOVE; LI, 2000).

Fontanini e Picchi (2003) enfatizam a preocupação com a redução de desperdício nos fluxos de materiais e informação em diferentes intervenientes da cadeia de suprimentos da construção. Segundo esses mesmos autores, os desperdícios assumem diversas formas ao longo da cadeia de suprimentos, podendo ser mensurados por meio de atrasos, entregas fora do prazo e das especificações, retrabalhos e ineficiências dentro dos processos.

No processo de impermeabilização, a escolha correta de determinado produto ou sistema, que desempenhe efetivamente suas funções, dependerá das condições de uso e da qualidade da execução. De acordo com a NBR 9575 (ABNT, 2003), o sistema de impermeabilização corresponde ao conjunto de produtos e serviços destinados a conferir estanqueidade às partes de uma construção. Nesse caso, é importante garantir que as atividades executadas em todo o processo estejam conforme as normas e procedimentos existentes, garantindo a proteção das construções (ABNT, 2003).

Caso essas proteções não sejam adequadamente previstas, ou se forem executadas de forma incorreta, a camada que deveria ser estanque se degradará com o tempo, expondo os componentes da construção a agentes agressivos, reduzindo sua vida útil. Nesses casos, é necessária a intervenção prematura com manutenções que contribuam para elevar o custo total da construção. Segundo Porcello (1998), o custo de uma impermeabilização na construção civil gira em torno de $1 \%$ a $3 \%$ do custo total da obra, entretanto esse valor pode variar entre $5 \%$ e $10 \%$, quando a impermeabilização não atender a seu objetivo, apresentando defeitos. Mais recentemente, Lima (2012) aferiu esses dados por meio de levantamento com dez empresas construtoras de Salvador e constatou que o custo médio da impermeabilização é $1,06 \%$ do custo total da obra.

Motivado pelas queixas generalizadas ao Procon da cidade de Recife a respeito de problemas de infiltração, o Conselho Regional de Engenharia, Agronomia e Arquitetura (Crea) de Pernambuco realizou um estudo detalhado em 335 edifícios em uso naquela cidade, com o objetivo de fazer um diagnóstico do problema e dos principais fatores envolvidos. Um dos resultados da pesquisa apontou que $78,5 \%$ dos edifícios apresentavam ou já tinham apresentado problemas de infiltração e que $25 \%$ deles apresentaram esse tipo de problema antes de completar dois anos de uso (CREA-PE, 1997).

De acordo com Moraes (2002), o Sindicato das Empresas de Compras, Vendas, Locação e Administração de Imóveis e dos Edifícios em Condomínios Residenciais e Comerciais do Estado de São Paulo (Secovi-SP) também efetuou um levantamento em 52 obras de oito construtoras e destacou que $90 \%$ dos problemas após a entrega das chaves estavam reunidos em cinco itens, sendo a impermeabilização o primeiro deles.

Ainda devem ser enfatizados os estudos de levantamentos patológicos, entre eles o estudo de Ioshimoto (1988), que indicaram a umidade como principal problema da edificação, evidenciado pelo fato de que, em $37 \%$ a $50 \%$ das patologias encontradas nas casas térreas, havia pelo menos uma falha parcial nos sistemas de revestimento.

É importante lembrar que as falhas em qualquer produto ou serviço, mesmo que prontamente recuperadas por equipes de manutenção e assistência técnica e totalmente cobertas por termos de garantia, causam, no mínimo, a 
insatisfação do consumidor, por privá-lo do uso do espaço por determinado tempo (SORTINO, 2005).

Com base no exposto, o sistema de impermeabilização, no que se refere ao processo integrado de projeto, aquisição de materiais e execução de uma edificação, deve ser percebido como uma oportunidade de melhoria para o adequado desempenho da edificação. Para isso, faz-se necessário um melhor entendimento de seu processo, bem como de seus fluxos, sejam de informação, pessoas ou materiais, para que sejam adotados padrões e processos gerenciais capazes de aumentar a eficiência de recursos técnicos, humanos e financeiros destinados à impermeabilização.

O presente artigo tem como objetivo principal sistematizar o processo de identificação de problemas relacionados à gestão integrada de projeto, aquisição e execução do sistema de impermeabilização, a partir de uma estrutura de análise com foco no fluxo de informação, no desperdício e no atendimento às normas em vigor.

A partir dessa estrutura e por meio de um levantamento de dados, foi realizada uma avaliação do processo integrado do sistema de impermeabilização visando identificar problemas e propor recomendações que permitam reduzir custos e desperdícios, com a consequente melhoria da qualidade.

A escolha do sistema de impermeabilização neste estudo é devido ao grande número de manutenção corretiva nas edificações para reparo das estruturas de concreto e outros componentes como anteriormente mencionado, bem como o desconhecimento por grande parte dos profissionais da construção civil sobre este tema e sua importância para a proteção das construções.

O foco deste estudo foi o processo integrado de impermeabilização nos edifícios residenciais, por se tratar do tipo de empreendimento com maior número de unidades construídas e por possuir maior quantidade de locais que requerem a impermeabilização, comparando-se às obras comerciais ou industriais.

\section{Aspectos técnicos do processo de impermeabilização}

O desafio da engenharia da impermeabilização é garantir a estanqueidade das partes construtivas que necessitem dela, a exemplo de lajes expostas, calhas, lajes molháveis internas, muros e pisos em contato com o solo, reservatórios e piscinas. A seguir são discutidos aspectos básicos relativos aos sistemas de impermeabilização.

\section{Sistemas de impermeabilização}

Na construção civil, em especial nos serviços de impermeabilização, alguns materiais têm destaque, como os asfaltos, as argamassas cimentícias e as resinas poliméricas, formando os principais sistemas de impermeabilização disponíveis no mercado. Segundo Yazigi (2009), a vida útil desses sistemas corresponde ao período que vai desde o término da execução da impermeabilização até o momento em que o sistema atinja o ponto de fadiga que comprometa seu desempenho sob as condições impostas.

Schlaepfer e Cunha (2001) orientam que conforme o tipo da estrutura, incluindo sua rigidez e sua situação em relação aos fluxos de água, entre outros fatores, diversos tipos de sistema de impermeabilização podem ser projetados, de modo a atender às necessidades do usuário no que diz respeito ao custo mais adequado.

Ischakewitsch (2013) destaca um conjunto de fatores a considerar na escolha dos materiais de impermeabilização, tais como: tamanho da obra; condição do substrato; aplicação a quente ou a frio; tempo de execução; mobilização de equipamentos; produção; acabamentos; sustentabilidade; agentes degradantes; logística; cronograma da obra. Entretanto, este mesmo autor ressalta que existirão condições específicas que exigirão maior atenção do projetista para o correto dimensionamento do sistema de impermeabilização.

De acordo com a NBR 9574 (ABNT, 2008), a execução de um sistema de impermeabilização deverá obedecer às exigências de cada tipo de sistema, conforme classificação definida na NBR 9575 (ABNT, 2003), em que os sistemas se subdividem em impermeabilização rígida e impermeabilização flexível.

\section{Aspectos do projeto de impermeabilização}

A seleção do sistema de impermeabilização e o projeto são definidos, no Brasil, com base na norma prescritiva NBR 9575 (ABNT, 2003). Essa norma tem como objetivo estabelecer as exigências e recomendações para atendimento das condições mínimas de proteção da construção contra a passagem de fluidos, garantindo a estanqueidade das partes construtivas que a requeiram. Segundo a referida norma, o projeto de impermeabilização deve ser composto de um projeto básico e de um projeto executivo.

Para garantir a execução e desempenho do sistema de impermeabilização, a NBR 9575 (ABNT, 2003) prescreve uma relação de detalhes construtivos ao 
qual o projeto de impermeabilização deve atender, evitando que decisões sejam tomadas durante sua execução, o que acarretaria atrasos e perdas desnecessárias (Quadro 1).

Souza e Melhado (1997), em seu trabalho sobre parâmetros para seleção e projeto do sistema de impermeabilização de pisos do pavimento-tipo de edifícios, afirmam que um projeto pode ser responsável por agregar eficiência e qualidade ao produto, atendendo aos interesses dos principais envolvidos no processo, como o empreendedor, o projetista, o construtor e o usuário. Os referidos autores consideram que a seleção do sistema de impermeabilização deve seguir as seguintes diretrizes:

(a) atender aos requisitos de desempenho;

(b) ter a máxima racionalização construtiva;

(c) garantir a máxima construtibilidade;

(d) demonstrar a adequação do sistema de impermeabilização aos demais subsistemas, elementos e componentes do edifício, especialmente a laje, o piso e a alvenaria; e

(e) possuir custo compatível com o empreendimento.
Outro fator que deve ser levado em consideração em um projeto de impermeabilização é a simplificação dele, ou seja, deve-se procurar estabelecer especificações dentro de um número limitado de opções que facilitem, no futuro, um controle de qualidade dos materiais (ISCHAKEWITSCH, 2013).

Além disso, para a qualidade de um projeto e o desempenho dos sistemas de impermeabilização, é importante considerar sua interferência com outros sistemas da construção, que, por muitas vezes, dificultam a instalação da impermeabilização ou comprometem sua função principal de estanqueidade. Yazigi (2009) relaciona em seu livro algumas interferências que necessitam ser equacionadas, ratificando detalhes construtivos estabelecidos na NBR 9575 (ABNT, 2003), tais como junta, soleira em área fria, caixão perdido, engaste no plano vertical (rodapé), ralo e tubulação que atravessa a impermeabilização.

Moraes (2002) destaca em seu trabalho que as falhas no sistema de impermeabilização podem ser decorrentes de deficiências no processo de projeto, como ausência do próprio projeto, especificação inadequada dos materiais e falta de análise das interferências de outros projetos no projeto de impermeabilização.

\section{Quadro 1 - Detalhes construtivos segundo a NBR 9575}

\begin{tabular}{|c|c|}
\hline \multirow{8}{*}{ Substrato } & - Inclinação mínima de $1 \%$ em direção aos coletores em áreas externas \\
\hline & - Para calhas e áreas internas, inclinação mínima de $0,5 \%$ \\
\hline & $\begin{array}{l}\text { - Nos planos verticais, prever encaixe para embuitr a impermeabilização, } 20 \\
\mathrm{~cm} \text { acima do nível do piso acabado }\end{array}$ \\
\hline & $\begin{array}{l}\text { Entre áreas externas impermeabilizadas e áreas internas, deve haver } \\
\text { diferença de cota no mínimo } 6 \%\end{array}$ \\
\hline & $\begin{array}{l}\text { - Observar arremates adequados com o tipo de impermeabilização nos } \\
\text { caixilhos, contramarcos, batentes e outros elementos }\end{array}$ \\
\hline & $\begin{array}{l}\text { Todo encontro de plano vertical e horizontal deve possuir detalhe } \\
\text { específico da impermeabilização }\end{array}$ \\
\hline & $\begin{array}{l}\text { - Os planos verticais a serem impermeabilizados devem ser executados } \\
\text { com elementos rigidamente solidarizados à estrutura }\end{array}$ \\
\hline & $\begin{array}{l}\text { - Prever arredondameto dos cantos vivos quando a impermeabilização } \\
\text { requerer }\end{array}$ \\
\hline \multirow{2}{*}{ Coletores de água (ralos) } & - Possuir diâmetro nominal mínimo de 75 mm \\
\hline & - Devem estar fixados à estrutura \\
\hline \multirow{4}{*}{$\begin{array}{l}\text { Tubos emergentes ou } \\
\text { passantes }\end{array}$} & $\begin{array}{l}\text { - Fixar à estrutura, possuindo detalhe específico de arremate e reforço da } \\
\text { impermeabilização }\end{array}$ \\
\hline & $\begin{array}{l}\text { - Devem ser fixados sobre a impermeabilização, e nunca sob elas, incluindo } \\
\text { tubulações elétricas e de gás }\end{array}$ \\
\hline & $\begin{array}{l}\text { - Quando for embutida na alvenaria, prevê proteção adequada para fixação } \\
\text { de impermeabilização }\end{array}$ \\
\hline & $\begin{array}{l}\text { - Quando forem externas à parede, devem estar afastadas dos planos } \\
\text { verticais em no mínimo } 10 \mathrm{~cm}\end{array}$ \\
\hline $\begin{array}{l}\text { Proteção mecânica e pisos } \\
\text { posteriores }\end{array}$ & $\begin{array}{l}\text { Devem possuir juntas de retração e trabalho térmico preenchidas com } \\
\text { materiais deformáveis }\end{array}$ \\
\hline \multirow[b]{2}{*}{ Juntas de dilatação } & - Devem ser divisores de água \\
\hline & $\begin{array}{l}\text { Prever detalhamento específico, principalmente quanto ao rebatimento de } \\
\text { sua abertura na proteção mecânica e nos pisos superiores }\end{array}$ \\
\hline
\end{tabular}

Fonte: ABNT (2003). 


\section{Aspectos do processo executivo da impermeabilização}

A norma brasileira NBR 9574 (ABNT, 2008) estabelece as exigências e recomendações relativas à execução dos serviços de impermeabilização para que sejam atendidas as condições mínimas de proteção da construção contra a passagem de fluidos, garantindo a estanqueidade das partes construtivas. A referida norma estabelece os seguintes requisitos gerais:

(a) áreas que requerem estanqueidade devem ser totalmente impermeabilizadas;

(b) deve ser garantida que a argamassa de regularização tenha idade mínima de sete dias para as impermeabilizações que exigem substrato seco;

e

(c) superfícies sujeitas à água sob pressão positiva devem receber a impermeabilização na face de atuação da água.

De acordo com a NBR 9574 (ABNT, 2008), para cada tipo de sistema, cuidados especiais devem ser tomados no que diz respeito à preparação do substrato, aplicação e proteção do tipo de impermeabilização, também conhecida como proteção mecânica. Essa proteção tem por finalidade impedir danos à impermeabilização, devido ao tráfego e à evaporação dos componentes voláteis dos materiais responsáveis por sua elasticidade, provocada pela incidência direta da radiação solar. Yazigi (2009) comenta que a proteção mecânica só é prescindível quando o sistema de impermeabilização adotado for autoprotegido.

O processo de execução da impermeabilização pode ser influenciado negativamente tanto pela má qualidade dos materiais, quanto pela má execução do serviço. Godóy e Barros (1997) destacam os defeitos que podem ser causados pela aplicação inadequada, destacando-se:

(a) falta de argamassa de regularização, caimento inadequado e possibilidade de perfuração da impermeabilização;

(b) não arredondamento de cantos e arestas nos encontros dos planos horizontais e verticais;

(c) execução da impermeabilização sobre base inapropriada, comprometendo a aderência;

(d) juntas com cantos cortantes que podem agredir a impermeabilização;

(e) uso de camadas grossas na aplicação da impermeabilização moldada in loco, para economia de tempo, dificultando a cura da emulsão; e (f) falhas nas emendas dos sistemas pré-moldados de impermeabilização.

\section{Aspectos da gestão da construção}

Este item apresenta conceitos de gestão da construção, destacando-se aspectos relacionados ao fluxo de informações e desperdícios, de forma a justificar sua aplicação na atividade de impermeabilização.

\section{Fluxo da informação}

Para Silva e Souza (2003), o projeto tem papel fundamental na qualidade e produtividade na construção. Os autores afirmam que a repetição e continuidade de operações são fatores-chave fortemente influenciados pelo projeto, devido à definição de características como:
(a) repetição de dimensão de vãos;
(b) modulação de paredes;
(c) dimensões de peças estruturais; e
(d) dimensões de componentes de vedações.

Souza, Bahia e Gunji (2004) estabelecem as seguintes etapas do processo de projeto de edificações:
(a) concepção: estudo preliminar de arquitetura;
(b) solução de interfaces: anteprojeto, projeto préexecutivo e projeto legal;

(c) detalhamento das soluções: projeto executivo e projeto para produção; e

(d) atividades pós-entrega: projeto "as-built".

$\mathrm{O}$ projeto de impermeabilização situa-se na etapa de solução de interfaces, na medida em que são desenvolvidos o projeto executivo e o projeto para produção. De maneira geral, nesta etapa o projeto é detalhado para gerar informações que possibilitem a execução do sistema (CODINHOTO, 2003).

De acordo com Fabrício (2002), os projetos executivos de diferentes subsistemas geralmente ocorrem de forma fragmentada, sequencial e com reduzida inter-relação entre os envolvidos. Isso tende a causar retrabalhos, pois cada modificação proposta por um projetista pode necessitar uma revisão e alteração de projetos já mais amadurecidos, principalmente se as interfaces entre os subsistemas não forem bem solucionadas nas fases anteriores. Rocha (2009) alerta para o fato de que o projetista, ao ser contratado, entrega o projeto de determinado produto, mas o problema é que não existe um projeto para a construção, que, 
por sua vez, se desenvolve somente durante a execução da obra, acarretando maiores custos.

Nesse contexto, é importante entender o projeto como processo, ou seja, como um fluxo de informações, desde a captação das necessidades do cliente até a conversão em projeto (KOSKELA; HUOVILA, 1997). Analisando-se sob esta ótica, esses mesmos autores destacam que as perdas podem ser devidas ao retrabalho, à transferência de informação e à espera por informação.

Para Peralta (2002), a preocupação com o projeto pode ser considerada um dos principais aspectos para melhorias da qualidade da edificação, como a diminuição de custos de produção, a diminuição de ocorrência de falhas tanto no produto quanto no processo e a otimização das atividades de execução.

Outro aspecto é a necessidade do aumento da transparência para a melhoria da eficiência do fluxo de informações. Para Koskela (1992), a transparência é um conceito orientado ao controle visual, que pode ser utilizado para gerar informações úteis para a melhoria de desempenho da produção, da qualidade e da organização do local de trabalho. $\mathrm{O}$ aumento da transparência do processo facilita a identificação de erros, ao mesmo tempo em que aumenta a disponibilidade de informações necessárias para a execução das atividades, além de ser uma forma de aumentar o envolvimento da mão de obra em atividades de melhorias (ISATTO et al., 2000).

\section{Perdas no processo produtivo}

Para Ohno (1997), um dos autores seminais do Sistema Toyota de Produção, a melhoria da eficiência está associada à redução dos desperdícios e eventualmente ao aumento da capacidade produtiva. Para o referido autor, capacidade produtiva é a soma do trabalho realizado na produção e o desperdício gerado. Dessa forma, o aumento dessa capacidade não remete ao aumento da força de trabalho, mas ao aumento da eficiência, por meio da redução do trabalho improdutivo. Assim, a eliminação do desperdício pode aumentar substancialmente a eficiência do processo (OHNO, 1997).

Com base nessa afirmação, Ohno (1997) e Formoso et al. (2002), a partir da adaptação para a construção civil, descrevem os seguintes desperdícios em um processo produtivo:

(a) perdas por superprodução: referem-se a "o quê", "quando" e "quanto" é produzido desnecessariamente, resultando inconvenientes, tais como aumento de estoques de produtos finais ou intermediários, uso antecipado de materiais ou produtos e geração de produtos defeituosos (OHNO, 1997);

(b) perdas por espera: relacionadas com a sincronização e o nivelamento dos fluxos de materiais e com as atividades dos trabalhadores. Podem envolver tanto perdas de mão de obra quanto de equipamentos, como, por exemplo, paradas nos serviços originadas por falta de disponibilidade de equipamentos ou de materiais (FORMOSO et al., 2002);

(c) perdas por transporte: referem-se às movimentações de objetos ou pessoas, geradas por realocações desnecessárias, leiaute inadequado, longa distância e outras causas, promovendo o uso de espaços desnecessários, queda de produtividade, aumento do custo de movimentação e geração de danos aos materiais (OHNO, 1997);

(d) perdas por processamento em si: têm origem na própria natureza das atividades do processo ou na execução inadequada deles. Decorrem da falta de procedimentos padronizados e ineficiências nos métodos de trabalho, da falta de treinamento da mão de obra ou de deficiências no detalhamento e construtividade dos projetos (FORMOSO et al., 2002);

(e) perdas por estoques: referem-se ao acúmulo de matérias-primas, componentes ou elementos de montagem em depósitos ou na própria linha, entre os processos, como estoque intermediário. Podem causar perdas de materiais quanto de capital (OHNO, 1997);

(f) perdas por movimento: são os movimentos não produtivos e desnecessários dos trabalhadores durante a execução das atividades (OHNO, 1997); e

(g) perdas devido à fabricação de produtos defeituosos: ocorrem quando são fabricados produtos que não atendem aos requisitos de qualidade especificados. Resultam em retrabalhos ou em redução do desempenho do produto final de projetos (FORMOSO et al., 2000).

Koskela (2004) propôs a oitava categoria de perda, denominada de making-do. Making-do refere-se à situação na qual a tarefa é iniciada sem todas as suas entradas necessárias disponíveis, ou a execução da tarefa é continuada, apesar da indisponibilidade de pelo menos uma das entradas necessárias (KOSKELA, 2004).

Mais recentemente, Fireman, Formoso e Isatto (2013) exploraram outra categoria adicional de perda, denominada de unfinished work $^{1}$. Este tipo de perda emergiu de observações realizadas em canteiros de obra, que inclui retrabalho e pequenos

${ }^{1}$ Pode ser traduzido por trabalho inacabado 
trabalhos deixados para trás pela equipe que estava realizando o pacote de trabalho (FIREMAN; FORMOSO; ISATTO, 2013). Para esses autores, ambos os eventos geram consequências como trabalho informal, aumento do trabalho em progresso, aumento das atividades que não agregam valor.

Por fim, o desperdício não deve ser visto apenas como consumo excessivo de materiais, e sim como toda perda no processo produtivo, além das perdas nos processos que antecedem a produção, como fabricação de materiais, preparação dos recursos humanos, projetos, planejamento e suprimentos (COLOMBO; BAZZO, 2001).

\section{Método de pesquisa}

O presente trabalho foi realizado por meio de levantamento de dados, com projetistas de impermeabilização, empresas construtoras e aplicadores de sistemas de impermeabilização na Região Metropolitana de Salvador, visando à análise do processo integrado de projeto, aquisição de materiais e execução da impermeabilização.

A pesquisa foi realizada a partir de quatro etapas de pesquisa (Figura 1):

(a) revisão bibliográfica;

(b) proposição de estrutura para análise do processo integrado da impermeabilização, baseado em princípios da construção enxuta e no atendimento às normas pertinentes;

(c) avaliação do processo integrado de impermeabilização, com base na estrutura proposta; e (d) análise dos dados.

Inicialmente foi realizada uma revisão da literatura sobre aspectos técnicos e normativos acerca de impermeabilização, bem como sobre construção enxuta, enfatizando conceitos relacionados a fluxo das informações e desperdício.

A partir dessa revisão, foi proposta uma estrutura de análise que pudesse representar as características investigadas no processo de projeto, aquisição e execução de sistemas de impermeabilização. Para a definição dessa estrutura foram estabelecidos três constructos: "fluxo de informação", "desperdício" e "conformidade". Esses constructos foram desdobrados em variáveis e critérios de avaliação para permitir a análise qualitativa do processo integrado do sistema de impermeabilização.

Segundo Martins e Pelissaro (2005), o constructo é um recurso metodológico que serve para explorar algum conceito teórico, baseando-se em variáveis observáveis e mensuráveis, cujo significado é construído intencionalmente a partir de determinado marco teórico.

O constructo "fluxo de informação" permitiu avaliar a transparência das informações (KOSKELA, 1992) no projeto, na aquisição e na execução, as relações de treinamento e conhecimento dentro de cada etapa do processo integrado do sistema de impermeabilização, bem como a coordenação entre os processos de projeto, aquisição e execução, focando a disseminação da informação.

\section{Figura 1 - Delineamento da pesquisa}

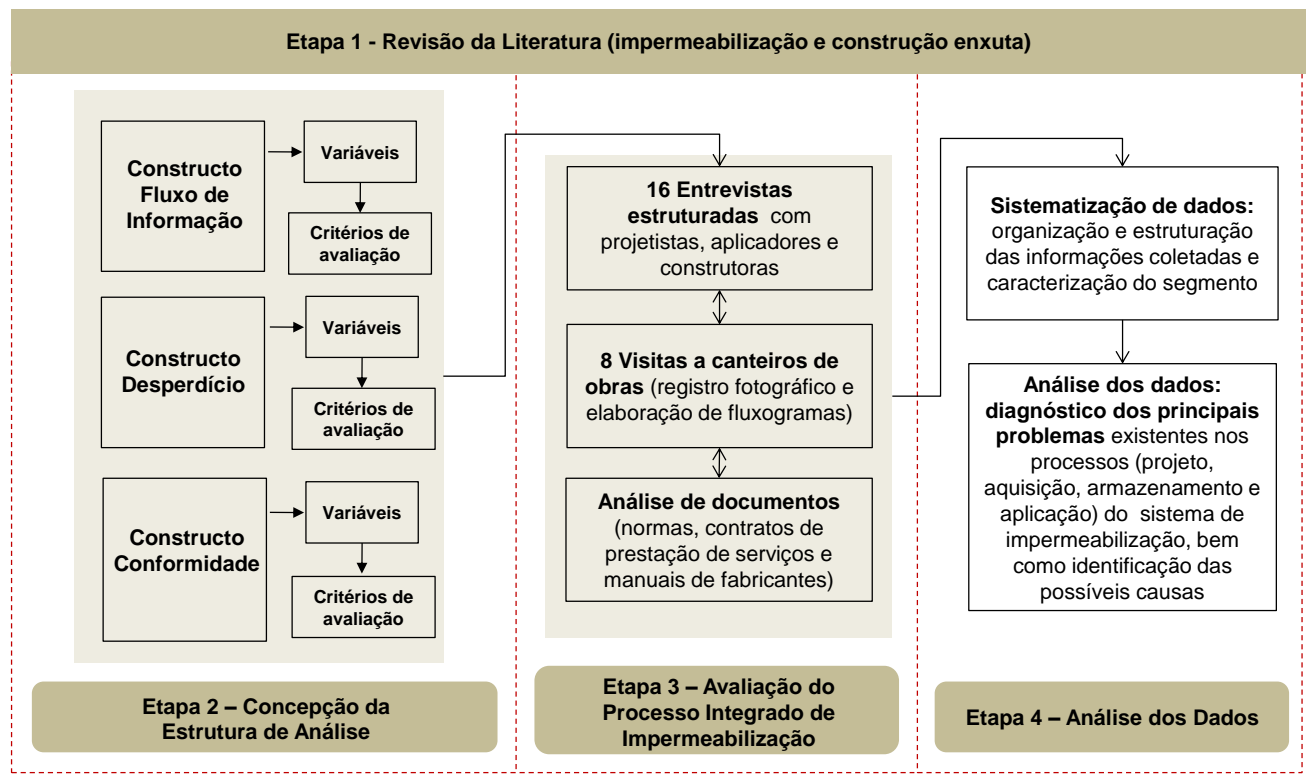


O constructo "desperdício" foi criado para identificar as principais perdas em cada etapa do processo integrado de impermeabilização, com base nas sete perdas estabelecidas por Ohno (1997). Não foram observadas neste trabalho as categorias mais recentes de perdas, denominadas making-do e unfinished work.

Por fim, a "conformidade" é um constructo relacionado ao cumprimento das prescrições estabelecidas nas normas relacionadas ao processo de impermeabilização (ABNT, 2003, 2008) e obediência aos projetos, especificações e procedimentos internos das empresas.

O Quadro 2 detalha os constructos, variáveis, critérios de avaliação e fontes de evidência utilizadas na pesquisa.

\section{Quadro 2 - Estrutura de Análise: constructos, variáveis, critérios de avaliação e fontes de evidência}

\begin{tabular}{|c|c|c|c|c|c|}
\hline \multirow{2}{*}{ CONSTRUCTO } & \multirow{2}{*}{ VARIÁVEIS } & \multicolumn{3}{|c|}{ CRITÉRIOS DE AVALIAÇÃO } & \multirow{2}{*}{$\begin{array}{l}\text { FONTES DE } \\
\text { EVIDÊNCIA }\end{array}$} \\
\hline & & PROJETO & AQUISIÇÃO & EXECUÇÃO & \\
\hline \multirow{4}{*}{$\begin{array}{l}\text { Fluxo de } \\
\text { informação }\end{array}$} & \multirow{2}{*}{ Transparência } & $\begin{array}{l}\text { Documento que evidencie } \\
\text { a definição dos sistemas }\end{array}$ & \multirow{2}{*}{$\begin{array}{c}\text { Existência de plano de } \\
\text { compras }\end{array}$} & $\begin{array}{c}\text { Visibilidade dos } \\
\text { procedimentos e } \\
\text { sequenciamento de } \\
\text { execução }\end{array}$ & \multirow{2}{*}{$\begin{array}{l}\text { Entrevistas, análise de } \\
\text { documentos, visitas às } \\
\text { obras com observação } \\
\text { direta, registro } \\
\text { fotográfico }\end{array}$} \\
\hline & & \begin{tabular}{|c|} 
Detalhes das \\
interferências com outros \\
processos
\end{tabular} & & $\begin{array}{c}\text { Identificação nas áreas a } \\
\text { impermeabilizar }\end{array}$ & \\
\hline & $\begin{array}{l}\text { Capacitação e } \\
\text { treinamento }\end{array}$ & $\begin{array}{c}\text { Apresentação e discussão } \\
\text { do projeto com os } \\
\text { envolvidos (contratante, } \\
\text { aquisição e execução) }\end{array}$ & \begin{tabular}{|c|} 
Conhecimento sobre \\
os materiais e serviços \\
a serem adquiridos
\end{tabular} & $\begin{array}{c}\text { Treinamento e orientação } \\
\text { sobre os serviços } \\
\text { executados }\end{array}$ & Entrevistas, percepção \\
\hline & Coordenação & $\begin{array}{c}\text { Coordenação e } \\
\text { acompanhamento do } \\
\text { projeto }\end{array}$ & $\begin{array}{l}\text { Coordenação de } \\
\text { compras }\end{array}$ & $\begin{array}{c}\text { Existência de liderança no } \\
\text { serviço }\end{array}$ & Entrevistas \\
\hline \multirow{11}{*}{ Desperdício } & \multirow{2}{*}{ Superprodução } & $\begin{array}{l}\text { Cálculos das áreas de } \\
\text { acordo com outros } \\
\text { projetos }\end{array}$ & \multirow{2}{*}{$\begin{array}{l}\text { Aquisição de material } \\
\text { conforme necessário }\end{array}$} & \multirow{2}{*}{$\begin{array}{c}\text { Aplicação em áreas de } \\
\text { acordo com o previsto em } \\
\text { projeto }\end{array}$} & \multirow{2}{*}{$\begin{array}{c}\text { Entrevistas, visitas às } \\
\text { obras com observação } \\
\text { direta }\end{array}$} \\
\hline & & $\begin{array}{c}\text { Projetos gerados de } \\
\text { acordo com a demanda do } \\
\text { contratante }\end{array}$ & & & \\
\hline & \multirow[b]{2}{*}{ Espera } & \begin{tabular}{|c|} 
Fornecimento de \\
informações necessárias \\
para realização do projeto
\end{tabular} & $\begin{array}{c}\text { Pontualidade na } \\
\text { definição dos produtos } \\
\text { para compra }\end{array}$ & $\begin{array}{l}\text { Operário com tempos } \\
\text { produtivos durante a } \\
\text { execução dos serviços }\end{array}$ & \multirow{2}{*}{$\begin{array}{l}\text { Entrevistas, visitas às } \\
\text { obras com observação } \\
\text { direta }\end{array}$} \\
\hline & & $\begin{array}{c}\text { Retorno das solicitações } \\
\text { nas definições de outros } \\
\text { projetos }\end{array}$ & $\begin{array}{c}\text { Aprovação da compra } \\
\text { sem espera }\end{array}$ & $\begin{array}{l}\text { Liberação de áreas para } \\
\text { excução dos serviços de } \\
\text { acordo com o } \\
\text { planejamento }\end{array}$ & \\
\hline & Transporte & - & $\begin{array}{l}\text { Armazenamento de } \\
\text { material próximo ao } \\
\text { local de aplicação }\end{array}$ & $\begin{array}{c}\text { Pouca movimentação dos } \\
\text { materiais durante a } \\
\text { execução dos serviços }\end{array}$ & $\begin{array}{l}\text { Entrevistas, visitas às } \\
\text { obras com observação } \\
\text { direta }\end{array}$ \\
\hline & Processamento em si & - & - & $\begin{array}{c}\text { Realizações de } \\
\text { operações apenas } \\
\text { necessárias }\end{array}$ & $\begin{array}{l}\text { Visitas às obras com } \\
\text { observação direta }\end{array}$ \\
\hline & \multirow[b]{2}{*}{ Estoque } & \multirow[b]{2}{*}{ - } & \multirow{2}{*}{$\begin{array}{c}\text { Aquisição de materiais } \\
\text { de acordo com a } \\
\text { demanda }\end{array}$} & Produção just in time & \multirow{2}{*}{$\begin{array}{c}\text { Entrevistas, visitas às } \\
\text { obras com observação } \\
\text { direta }\end{array}$} \\
\hline & & & & $\begin{array}{c}\text { Uso apenas de espaço } \\
\text { necessário }\end{array}$ & \\
\hline & $\begin{array}{l}\text { Movimento não } \\
\text { produtivo }\end{array}$ & - & - & $\begin{array}{l}\text { Disponibilidade dos } \\
\text { materiais e } \\
\text { sequenciamento de } \\
\text { execução dos serviços }\end{array}$ & $\begin{array}{l}\text { Entrevistas, visitas às } \\
\text { obras com observação } \\
\text { direta }\end{array}$ \\
\hline & \multirow{2}{*}{ Retrabalho (defeitos) } & \multirow{2}{*}{$\begin{array}{c}\text { Ajustes no projeto após } \\
\text { término devido a } \\
\text { mudanças em outros } \\
\text { projetos que possuem } \\
\text { interface com a } \\
\text { impermeabilização }\end{array}$} & \multirow{2}{*}{$\begin{array}{l}\text { Produto não defeituoso } \\
\text { no recebimento }\end{array}$} & $\begin{array}{l}\text { Utilização de técnicas } \\
\text { recomendadas nas } \\
\text { operações }\end{array}$ & \multirow{2}{*}{$\begin{array}{l}\text { Entrevistas, análise de } \\
\text { documentos, visitas às } \\
\text { obras com observação } \\
\text { direta, registro } \\
\text { fotográfico }\end{array}$} \\
\hline & & & & $\begin{array}{c}\text { Baixa manutenção devido } \\
\text { à qualidade processo }\end{array}$ & \\
\hline \multirow{3}{*}{ Conformidade } & $\begin{array}{l}\text { Atendimento às } \\
\text { normas }\end{array}$ & $\begin{array}{c}\text { Definição e detalhamento } \\
\text { do projeto conforme as } \\
\text { normas }\end{array}$ & - & $\begin{array}{l}\text { Execução das atividades } \\
\text { conforme as normas e } \\
\text { procedimentos }\end{array}$ & $\begin{array}{c}\text { Entrevistas, análise de } \\
\text { documentos, visitas às } \\
\text { obras com observação } \\
\text { direta }\end{array}$ \\
\hline & $\begin{array}{l}\text { Atendimento ao } \\
\text { projeto }\end{array}$ & - & $\begin{array}{c}\text { Aquisição de materiais } \\
\text { conforme especificação } \\
\text { do projeto }\end{array}$ & $\begin{array}{l}\text { Utilização dos sistemas } \\
\text { conforme projeto }\end{array}$ & $\begin{array}{c}\text { Entrevistas e análise de } \\
\text { documentos }\end{array}$ \\
\hline & Garantia de qualidade & - & - & $\begin{array}{c}\text { Inspeção, identificação de } \\
\text { não conformidade e } \\
\text { retroalimentação }\end{array}$ & $\begin{array}{c}\text { Entrevistas e visitas às } \\
\text { obras com observação } \\
\text { direta }\end{array}$ \\
\hline
\end{tabular}

66 Lima, J. L. de A.; Passos, F. U.; Cosa, D. B. 
Para a avaliação do processo integrado do sistema de impermeabilização foram utilizadas múltiplas fontes de evidência, visando assegurar a qualidade dos dados e aumentar a confiabilidade da pesquisa (EASTERBY-SMITH; THORPE; LOWE， 1991; YIN, 2001). As principais fontes utilizadas foram questionários, análise de documentos, observação direta e registros fotográficos.

Foram aplicados três diferentes tipos de questionário, estruturados com questões fechadas e abertas, direcionados aos três diferentes intervenientes estudados, quais sejam, projetistas, construtoras e aplicadores, focando em seus respectivos processos: projeto, aquisição e execução. Entretanto, é importante destacar que as respostas dos diferentes intervenientes contribuíram para o entendimento das diferentes etapas do processo de impermeabilização como um todo.

No total, foram realizadas dezesseis entrevistas com os três intervenientes, conforme descrito a seguir:

(a) dois projetistas de impermeabilização, sendo os respondentes os próprios sócios das empresas e técnicos responsáveis diretos pelos projetos de impermeabilização, o que deu maior confiabilidade nas respostas obtidas. Durante essas entrevistas foram ainda analisados documentos como projetos, manual de fabricante e especificações técnicas;

\section{(b) dez construtoras sindicalizadas da Região} Metropolitana de Salvador, que representam os intervenientes que contratam o projeto, adquirem e disponibilizam os materiais e contratam os serviços de impermeabilização, que, neste caso, são cem por cento terceirizados. As entrevistas foram realizadas com os profissionais que tinham o maior conhecimento sobre as atividades da empresa em relação à impermeabilização, de forma que pudessem contribuir com respostas confiáveis. Foram ouvidos seis gerentes de contrato e quatro gerentes de obra, todos com formação em engenharia civil. Durante as entrevistas também foram analisados documentos como contratos de serviço, procedimentos de execução, projetos, especificações técnicas e manuais de fabricante. Quatro dessas empresas estavam com processo de impermeabilização em andamento e disponibilizaram seus canteiros para observação direta, para extrair informações sobre a execução dos serviços de impermeabilização.

Essas visitas envolveram ainda registro fotográfico; e

(c) quatro aplicadores de empresas especializadas em impermeabilização na cidade de Salvador, caracterizadas como micro e pequenas empresas, mas algumas delas com grandes contratos de prestação de serviço. A atividade profissional de um dos autores do artigo facilitou a aproximação com essas empresas, procurando-se selecionar as mais estruturadas e as que possuíam contratos com as maiores obras. Das cinco maiores empresas de impermeabilização de Salvador, quatro foram entrevistadas, o que possibilitou uma boa representatividade desse interveniente no processo de impermeabilização. Além das entrevistas, foi realizada a visita à obra com registro fotográfico, análise de documentos e observação direta da execução do serviço de impermeabilização.

As respostas às perguntas dos questionários referentes aos critérios de avaliação foram tabuladas para cada etapa do processo do sistema de impermeabilização. Essa tabulação obedeceu ao critério de favorabilidade das respostas, o qual representa o grau de aproximação dos critérios de avaliação em relação às práticas de gestão tidas como excelentes.

As alternativas de respostas dos questionários permitiram classificá-las, sempre, como:

(a) positivas em relação às práticas prescritas para os critérios de avaliação (denominadas sim);

(b) parcialmente positivas (denominadas parcial); ou

(c) negativas em relação às práticas para os critérios (denominadas não).

Foi calculado o índice de favorabilidade das respostas, representado pelo percentual de respostas que convergiam positivamente para as prescrições do critério avaliado. As respostas "sim" receberam pontuação 1 (um); as respostas "parcial" receberam pontuação 0,5 (meio); e as respostas "não" receberam pontuação 0 (zero). Construiu-se uma tabela para cada processo (projeto, aquisição e execução), informando o percentual de favorabilidade (aderência às prescrições), que foi dado pela soma de todos os pontos obtidos pelo indicador dividido pelo número de empresas do processo investigado.

\section{Apresentação dos resultados}

A partir da tabulação dos resultados obtidos com as empresas de projeto, aquisição de materiais e execução da impermeabilização, foi realizada uma avaliação de cada um dos processos, de forma a identificar os pontos positivos e as oportunidades de melhorias, conforme estrutura de análise proposta. 


\section{Avaliação do processo de projeto de impermeabilização}

A Tabela 1 apresenta os percentuais de favorabilidade dos critérios de avaliação investigados para o processo de projeto, a partir dos dados coletados com as empresas de projetos A e B.

Dos 10 (dez) critérios propostos para analisar o processo de projeto, apenas 4 (quatro) deles tiveram percentual de favorabilidade acima ou igual a $75 \%$, sendo eles:

(a) detalhes das interferências com outros projetos;

(b) projeto gerado de acordo com a demanda do contratante;

(c) fornecimento de informações necessárias para a realização do projeto; e

(d) definição e detalhamento do projeto conforme as normas.

Os outros seis critérios de avaliação obtiveram índice de favorabilidade abaixo de $75 \%$, destacando-se com $0 \%$ de favorabilidade os seguintes critérios:

(a) apresentação e discussão do projeto junto ao contratante;

(b) coordenação e acompanhamento da execução do projeto; e

(c) retorno das solicitações relativas à definição de outros projetos.

Pelos resultados obtidos, observa-se que os maiores problemas em projeto estão relacionados a fluxo das informações (quatro critérios com baixa aderência às prescrições) e ao desperdício (três critérios com baixa aderência às prescrições).
Percebe-se ainda que a conformidade, em relação às normas, está sendo cumprida.

A falta de apresentação, discussão e acompanhamento do projeto pode gerar erros de entendimento das especificações com reflexo na execução. Além disso, a dificuldade que os projetistas têm para receber as informações solicitadas acarreta atrasos nos projetos ou são gerados projetos incompletos. Foi evidenciado nas visitas às obras que algumas soluções dessas interfaces são dadas na obra durante a execução da impermeabilização.

Uma das evidências de desperdícios no processo de projeto está no erro de cálculo das áreas das superfícies a serem impermeabilizadas, provocado pelo fornecimento de informações inconsistentes por parte do projeto arquitetônico. Apesar de não ser uma questão de superprodução de projeto, esse critério é avaliado na etapa de projeto com repercussão no processo de aquisição.

A principal fonte de desperdício no processo de projeto foi a espera. Pode ser evidenciado espera no fornecimento de informações aos projetistas solicitadas às construtoras, principalmente em relação a alterações de outros projetos que tenham interface com a impermeabilização. Além disso, contatou-se retrabalho para modificações no projeto de impermeabilização após ser concluído, em função de alterações nos demais projetos.

A partir dos resultados obtidos e tomando-se como base as evidências obtidas nas entrevistas, visitas, observação direta e análise de documentos, foi elaborado o Quadro 3, que apresenta um resumo da avaliação do processo de projeto, destacando-se os pontos positivos e as oportunidades de melhorias desse processo.

Tabela 1 - Análise da favorabilidade dos critérios de avaliação - processo de projeto

\begin{tabular}{|c|c|c|c|c|c|c|c|c|c|c|}
\hline Empresa & \multicolumn{4}{|c|}{--- Fluxo de Informação --o- } & \multicolumn{5}{|c|}{ 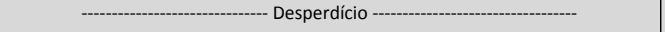 } & \begin{tabular}{|c|}
-- Conformidade -- \\
\\
Definição e \\
detalhamento do \\
projeto conforme \\
as normas
\end{tabular} \\
\hline B & parcial & $\operatorname{sim}$ & não & não & parcial & parcial & parcial & não & parcial & $\operatorname{sim}$ \\
\hline $\begin{array}{c}\text { Índice de } \\
\text { favorabi- } \\
\text { lidade dos } \\
\text { indicadores }\end{array}$ & $50 \%$ & $75 \%$ & $0 \%$ & $0 \%$ & $50 \%$ & $75 \%$ & $75 \%$ & $0 \%$ & $50 \%$ & $100 \%$ \\
\hline
\end{tabular}

68 Lima, J. L. de A.; Passos, F. U.; Cosa, D. B. 
Quadro 3 - Pontos positivos e oportunidades de melhoria no processo de projeto

\begin{tabular}{|c|c|c|}
\hline CONSTRUCTO & PONTOS POSITIVOS & OPORTUNIDADES DE MELHORIA \\
\hline \multirow{4}{*}{ Fluxo de informação } & \multirow[t]{4}{*}{$\begin{array}{l}\text { Detalhamento das interferências } \\
\text { com outros projetos }\end{array}$} & $\begin{array}{l}\text { Dificuldades no recebimento de informações solicitadas para } \\
\text { elaboração do projeto }\end{array}$ \\
\hline & & $\begin{array}{l}\text { Falta de quadro-resumo com locais, áreas }\left(\mathrm{m}^{2}\right) \text {, sistemas } \\
\text { adotados e quantidade de materiais }\end{array}$ \\
\hline & & $\begin{array}{l}\text { Desconhecimento por parte da construtora e empresa de } \\
\text { aplicação sobre o projeto de impermeabilização e suas } \\
\text { definições }\end{array}$ \\
\hline & & $\begin{array}{l}\text { Falta de acompanhamento da execução dos serviços de } \\
\text { impermeabilização pela empresa de projeto }\end{array}$ \\
\hline \multirow{3}{*}{ Desperdício } & \multirow[t]{3}{*}{$\begin{array}{l}\text { Dedicação de tempo para } \\
\text { elaboração do projeto }\end{array}$} & $\begin{array}{l}\text { Divergência entre as áreas do projeto de impermeabilização e } \\
\text { a área real na obra }\end{array}$ \\
\hline & & $\begin{array}{l}\text { Projeto gerado em desacordo com a demanda do cliente } \\
\text { (construtora) }\end{array}$ \\
\hline & & $\begin{array}{l}\text { Número de revisões no projeto em função de alterações em } \\
\text { outros projetos }\end{array}$ \\
\hline Conformidade & $\begin{array}{l}\text { Projetos elaborados em } \\
\text { cumprimento às normas de imper- } \\
\text { meabilização }\end{array}$ & \\
\hline
\end{tabular}

Observa-se que os pontos mais críticos, que são os responsáveis por boa parte das oportunidades de melhorias no processo de projeto, estão relacionados à disponibilidade das informações solicitadas pelos projetistas para a execução do projeto de impermeabilização. Apesar disso, o nível de detalhamento nos projetos de impermeabilização apresentou-se satisfatório, pois os projetistas entrevistados procuram detalhar seus projetos com base nas informações recebidas, mesmo que estas estejam incompletas ou defasadas.

Outra oportunidade de melhoria para esse processo é a coordenação e o acompanhamento do projeto na obra, que pode possibilitar o maior controle dos serviços realizados de acordo com as orientações previstas no projeto.

\section{Avaliação do processo de aquisição de materiais para impermeabilização}

A Tabela 2 apresenta os percentuais de favorabilidade dos critérios de avaliação investigados em cada constructo para o processo de aquisição de materiais pela construtora.

Observa-se que apenas três dos critérios apresentados na Tabela 2 obtiveram percentuais de favorabilidade iguais ou superiores a $75 \%$, com destaque para:

(a) coordenação das compras;

(b) pontualidade na definição dos produtos para compra; e (c) aquisição de materiais conforme as especificações.

Em relação aos critérios de avaliação a que não atenderam, destacam-se:

(a) o nível de conhecimento sobre os materiais e serviços adquiridos;

(b) a aquisição de material de acordo com o necessário;

(c) o armazenamento de material em local próximo da aplicação; e

(d) a aquisição de materiais de acordo com a demanda.

Pelos resultados obtidos, percebe-se novamente que o fluxo das informações (um critério com baixa aderência às prescrições) e os desperdícios (três critérios com baixa aderência às prescrições) são os problemas mais evidentes no processo de aquisição, não havendo problemas significativos quanto à conformidade.

Vale ressaltar que, apesar do pouco conhecimento sobre os materiais adquiridos, as empresas construtoras procuram cumprir o que estabelecem as especificações de projeto quando adquirem os produtos. Notou-se pelas entrevistas e observação direta que a aquisição em excesso de materiais pode ser reflexo do erro na quantificação durante o processo de projeto. Além disso, o armazenamento de material distante do local de aplicação e a aquisição de materiais antes da necessidade foram considerados como outras fontes de desperdícios. 
Pôde-se observar, também, desperdícios em relação ao tempo de espera para aprovação da compra. Identificou-se, por meio das entrevistas, que esse desperdício está relacionado, em sua maioria, ao excesso de pessoas envolvidas nessa atividade. Segundo os entrevistados, isso ocorre quando a diretoria é envolvida nessa atividade ou quando existe uma empresa gerenciadora da obra, que tem como papel fiscalizar e gerir os recursos financeiros da obra.

O Quadro 4 apresenta os pontos positivos observados no processo de aquisição dos sistemas de impermeabilização, bem como as oportunidades de melhorias que passam a ser um objeto de análise para implementação de ações específicas.

De modo geral, de acordo com as empresas construtoras entrevistadas, há uma sinalização da necessidade de aumentar o conhecimento sobre os produtos e serviços de impermeabilização adquiridos. Além disso, percebe-se a necessidade de promover melhorias nos processos internos de gestão de compras, a fim de evitar atrasos na compra com consequências no recebimento de materiais, bem como evitar a compra sem a necessidade imediata, que pode gerar perdas e danos aos materiais no armazenamento, principalmente distantes dos locais de aplicação.

\section{Avaliação do processo de execução da impermeabilização}

As Tabelas 3 e 4 apresentam os percentuais de favorabilidade dos critérios de avaliação investigados no processo de execução da impermeabilização.

Tabela 2 - Análise da favorabilidade dos critérios de avaliação - processo de aquisição

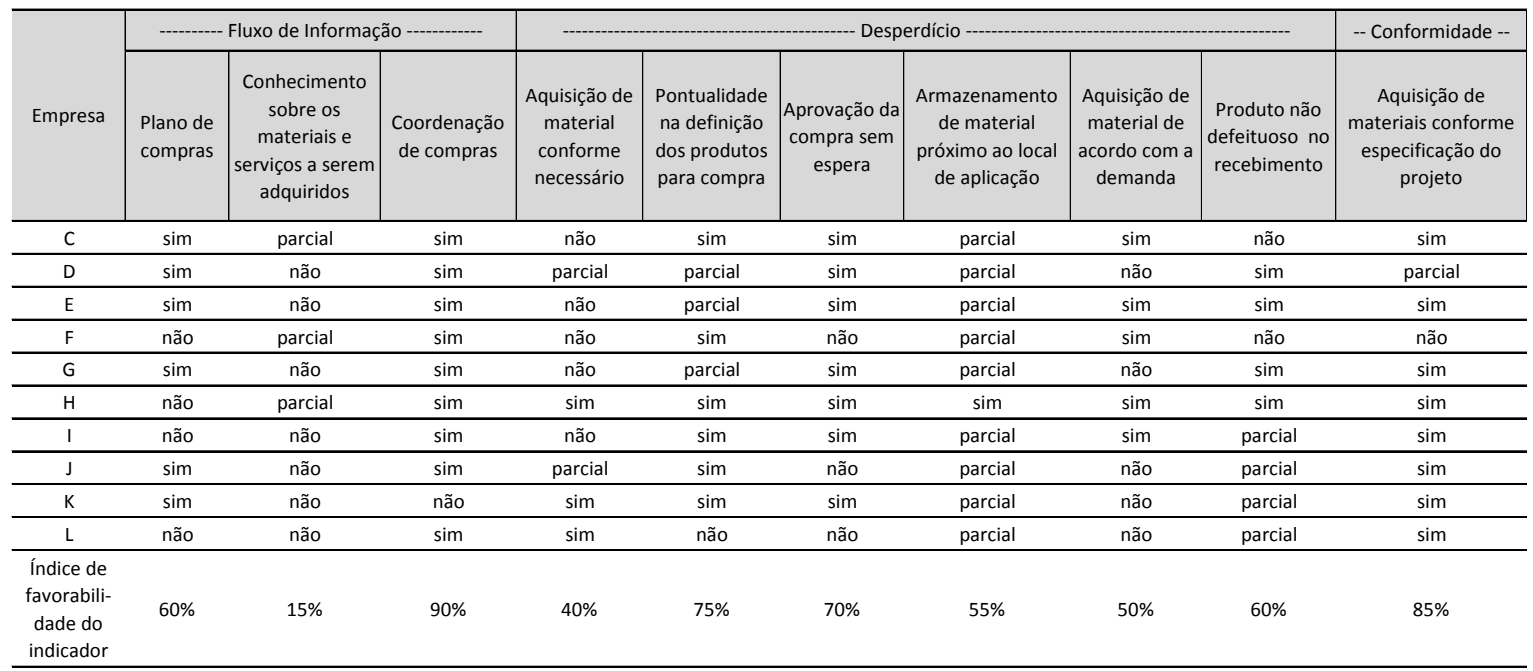

\section{Quadro 4 - Pontos positivos e oportunidades de melhoria no processo de aquisição}

\begin{tabular}{|c|c|c|}
\hline CONSTRUCTO & PONTOS POSITIVOS & OPORTUNIDADES DE MELHORIA \\
\hline \multirow[b]{2}{*}{ Fluxo de informação } & \multirow{2}{*}{$\begin{array}{l}\text { Existência de uma coordenação de } \\
\text { compras }\end{array}$} & Falta de um plano de compras \\
\hline & & $\begin{array}{l}\text { Pouco conhecimento sobre os materiais e serviços que são } \\
\text { adquiridos pela construtora }\end{array}$ \\
\hline \multirow{6}{*}{ Desperdício } & \multirow{6}{*}{$\begin{array}{l}\text { Agilidade na definição dos } \\
\text { produtos para compra }\end{array}$} & Sobra de material de impermeabilização na obra \\
\hline & & Espera para aprovação da compra \\
\hline & & $\begin{array}{l}\text { Disponibilização de material em local distante da área a ser } \\
\text { utilizado }\end{array}$ \\
\hline & & $\begin{array}{l}\text { Excesso de pessoas envolvidas no processo de aprovação da } \\
\text { compra }\end{array}$ \\
\hline & & Aquisição dos materiais antes da necessidade de uso \\
\hline & & Não conformidades no recebimento dos materiais \\
\hline Conformidade & $\begin{array}{l}\text { Aquisição dos materiais conforme } \\
\text { projeto e especificação }\end{array}$ & \\
\hline
\end{tabular}

70 Lima, J. L. de A.; Passos, F. U.; Cosa, D. B. 
Tabela 3 - Análise da favorabilidade dos critérios de avaliação - processo de execução

\begin{tabular}{|c|c|c|c|c|c|c|c|c|c|c|c|c|c|c|}
\hline \multirow[b]{2}{*}{ Empresa } & \multicolumn{4}{|c|}{ 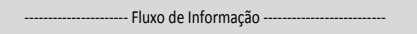 } & \multicolumn{10}{|c|}{ - Desperdicio } \\
\hline & $\begin{array}{l}\text { Visibilidade dos } \\
\text { procedimentos e } \\
\text { sequenciamento } \\
\text { da execução }\end{array}$ & $\begin{array}{c}\text { Identificação nas } \\
\text { áreas a } \\
\text { impermeabilizar }\end{array}$ & $\begin{array}{c}\text { Treinamento } \\
\text { de equipe e } \\
\text { orientação } \\
\text { sobre os } \\
\text { serviços }\end{array}$ & \begin{tabular}{|c|} 
Existência \\
de líderes \\
dos \\
serviços
\end{tabular} & \begin{tabular}{|c|} 
Aplicação \\
em áreas \\
de acordo \\
como o \\
previsto em \\
projeto
\end{tabular} & \begin{tabular}{|c|} 
Operários \\
com tempos \\
produtivos \\
durante a \\
execução \\
dos serviç̧os
\end{tabular} & $\begin{array}{l}\text { Liberação de } \\
\text { áreas para } \\
\text { execcusão de } \\
\text { acordo com o } \\
\text { planejamento }\end{array}$ & $\begin{array}{c}\text { Pouca } \\
\text { movimentação } \\
\text { dos materiais } \\
\text { durante a } \\
\text { execução dos } \\
\text { serviços }\end{array}$ & $\begin{array}{c}\text { Realização de } \\
\text { operações } \\
\text { apenas } \\
\text { necessárias }\end{array}$ & $\begin{array}{c}\text { Produção } \\
\text { just in } \\
\text { time }\end{array}$ & $\begin{array}{l}\text { Uso apenas } \\
\text { de espaços } \\
\text { necessários }\end{array}$ & $\begin{array}{c}\text { Disponibilidade dos } \\
\text { materiais e } \\
\text { sequenciamento de } \\
\text { execução dos } \\
\text { serviços }\end{array}$ & $\begin{array}{l}\text { Utilização de } \\
\text { técnicas } \\
\text { recomendadas } \\
\text { nas operações }\end{array}$ & $\begin{array}{c}\text { Baixa } \\
\text { manutenção } \\
\text { devido a } \\
\text { falhas no } \\
\text { processo }\end{array}$ \\
\hline 0 & não & não & não & $\operatorname{sim}$ & sim & não & não & parcial & sim & parcial & $\operatorname{sim}$ & $\operatorname{sim}$ & não & parcial \\
\hline $\mathrm{P}$ & não & não & parcial & $\operatorname{sim}$ & - & não & não & parcial & sim & sim & sim & parcial & não & parcial \\
\hline $\begin{array}{l}\text { Índice de } \\
\text { Favorabili- } \\
\text { dade do } \\
\text { indicador }\end{array}$ & $0 \%$ & $0 \%$ & $38 \%$ & $100 \%$ & $100 \%$ & $0 \%$ & $0 \%$ & $25 \%$ & $100 \%$ & $38 \%$ & $50 \%$ & $88 \%$ & $25 \%$ & $50 \%$ \\
\hline
\end{tabular}

Tabela 4 - Análise da favorabilidade dos critérios de avaliação - processo de execução

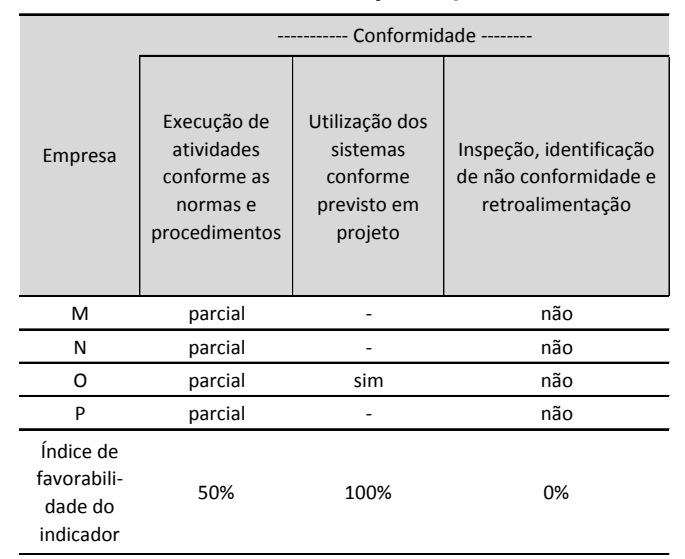

Nota: 1 - o item utilização dos sistemas conforme previsto em projeto não foi considerado para as empresas $M, N$ e $P$, pois a obra não possuia projeto.

Apenas três dos critérios avaliados apresentaram percentual de favorabilidade acima de $75 \%$, destacando-se:

(a) existência de liderança no serviço;

(b) realização de operações apenas necessárias; e

(c) disponibilidade dos materiais e sequenciamento na execução dos serviços.

Os critérios "utilização dos sistemas conforme previsto em projeto" e "aplicação em áreas não previstas em projeto" obtiveram $100 \%$ de favorabilidade, mas foram desconsiderados, pois não se aplicaram a três das empresas entrevistadas, pelo fato de a obra em que o serviço estava sendo executado não possuir projeto de impermeabilização.

Os demais 12 critérios de avaliação obtiveram um baixo índice de favorabilidade, sinalizando necessidade de melhorias, com destaque para cinco deles, cujo índice foi de $0 \%$, quais sejam:

(a) visibilidade dos procedimentos e sequenciamento da execução dos serviços;

(b) identificação nas áreas a impermeabilizar; (c) operários com tempo produtivo durante a execução dos serviços;

(d) liberação de área para execução de serviços de acordo com o planejamento; $\mathrm{e}$

(e) inspeção, identificação de não conformidade e retroalimentação.

Durante as visitas aos canteiros de obras, observou-se que a falta de sinalização nos locais de aplicação dos sistemas de impermeabilização permitia que esses locais fossem facilmente transitáveis por pessoas e equipamentos. Esse trânsito pode causar danos aos materiais aplicados antes de estar protegidos, como exige a norma NBR 9575 (ABNT, 2003).

Outra observação, com base nas visitas e entrevistas com as empresas de aplicação, foi a deficiência na capacitação dos operários, pois, segundo a maioria dos entrevistados, essa atividade não é praticada formalmente. Notou-se a realização de tarefas, durante a execução que não condizem com as orientações das normas e procedimentos. Dessa forma, evidenciou-se que existe fragilidade nos treinamentos das equipes que 
executam os serviços, sendo esse um dos critérios de avaliação com baixo índice de favorabilidade. Vale ressaltar que os problemas mencionados referem-se a deficiências com relação ao fluxo de informação no processo de execução.

Boa parte das oportunidades de melhoria está associada às atividades que geram desperdício, conforme o Quadro 5. Destaca-se o desperdício de materiais ao ser aplicado em locais ainda não liberados, movimento excessivo de materiais, que pode gerar perda, recurso humano parado por não ter área para trabalhar, descumprimento às normas e procedimentos de execução, o que provavelmente acarretará erros de execução, com consequente desperdício de recursos material e humano, além da falta de inspeção e identificação de não conformidade para retroalimentação do processo.

Os pontos positivos observados no processo de execução dos sistemas de impermeabilização estão relacionados, principalmente, à presença de líderes de serviços e à realização de operações apenas necessárias durante a execução. No entanto, conforme observado, existe uma limitação em termos de conhecimento sobre o processo, por parte desses líderes, de forma que sua presença pouco contribui para a qualidade do serviço executado.

Cabe observar que a utilização de sistemas conforme projeto é um ponto positivo, mas não é representativo para o universo das empresas entrevistadas, pois a maioria delas não tinha um projeto de impermeabilização na obra.

\section{Discussão dos resultados com base na estrutura de avaliação}

A partir das avaliações dos três processos que compõem o sistema de impermeabilização e com base na estrutura proposta, apresenta-se uma discussão dos resultados alinhada com os conceitos de gestão da construção apresentados na revisão bibliográfica.

\section{Fluxo de informação no processo integrado de impermeabilização}

Pôde-se observar que as deficiências no fluxo de informação iniciam-se na elaboração do projeto de impermeabilização, pois as informações dos outros projetos, necessárias para o conhecimento da obra, muitas vezes, chegam incompletas ao projetista de impermeabilização.

No decorrer da elaboração do projeto de impermeabilização são feitas alterações nos outros projetos que possuem interface na impermeabilização, as quais, às vezes, não são disponibilizadas a tempo para que sejam consideradas na impermeabilização. Com isso, pode-se gerar um projeto de impermeabilização incorreto ou incompleto, devido à falha na análise e na seleção das melhores soluções para as interfaces com os outros sistemas da obra. Algumas dessas interfaces são solucionadas na obra, conforme apresentado nos resultados, podendo comprometer a qualidade, o custo e o cronograma dos serviços de impermeabilização.

\section{Quadro 5 - Pontos positivos e oportunidades de melhoria no processo de execução}

\begin{tabular}{|c|c|c|}
\hline CONSTRUCTO & PONTOS POSITIVOS & OPORTUNIDADES DE MELHORIA \\
\hline \multirow{2}{*}{ Fluxo de informação } & \multirow[t]{2}{*}{ Presença de líderes de serviços } & $\begin{array}{l}\text { Falta de transparência do processo de execução (procedimentos } \\
\text { visíveis e sinalizações) }\end{array}$ \\
\hline & & $\begin{array}{l}\text { Deficiência na capacitação dos operários e orientação sobre os } \\
\text { serviços }\end{array}$ \\
\hline \multirow{7}{*}{ Desperdício } & \multirow{7}{*}{$\begin{array}{l}\text { Uso somente de operações } \\
\text { necessárias }\end{array}$} & Trabalho em locais sem preparação de área \\
\hline & & Trabalhador parado aguardando material no local de trabalho \\
\hline & & Trabalhador parado esperando liberação de área \\
\hline & & Excesso de movimentação de materiais \\
\hline & & Uso de espaços desnecessários \\
\hline & & Prática de técnicas não recomendadas \\
\hline & & Retorno prematuro para manutenção corretiva \\
\hline \multirow{2}{*}{ Conformidade } & \multirow[t]{2}{*}{$\begin{array}{l}\text { Utilização dos sistemas conforme } \\
\text { projeto (quando existe) }\end{array}$} & Descumprimento às normas e procedimentos de execução \\
\hline & & Falta de inspeção dos serviços \\
\hline
\end{tabular}

72 Lima, J. L. de A.; Passos, F. U.; Cosa, D. B. 
Além da deficiência no fluxo de informação entre as construtoras e as empresas de projeto de impermeabilização, observou-se que o produto final do projeto, que é entregue à construtora, não é apresentado e discutido com as partes envolvidas. Essa comunicação é importante para verificar se todas as necessidades foram atendidas e se as soluções de impermeabilização apresentadas são realmente as mais adequadas em relação ao desempenho, custo, manutenção e construtibilidade.

A capacitação dos profissionais envolvidos na execução do sistema de impermeabilização, apesar de não ser uma atividade que agregue valor ao produto final de forma direta, é considerada por Isatto et al. (2000) essencial para a eficiência global de determinado processo. Nesse caso, a capacitação no processo de impermeabilização é de fundamental importância para a melhoria da qualidade da execução dos serviços, com consequência direta no desempenho e durabilidade dos sistemas de impermeabilização aplicados.

Outra questão de suma importância para qualquer atividade produtiva é a transparência do processo, conforme argumentado por Koskela (1992). Nesse estudo, foi observado que não existe preocupação para que o processo de execução da impermeabilização seja transparente. As atividades na execução são de conhecimento bastante restrito por parte das empresas de aplicação, com pouca exposição dos procedimentos utilizados, bem como deficiência de sinalização nas áreas trabalhadas.

Como não existe transparência no processo de execução da impermeabilização, muitos erros cometidos passam despercebidos pelas pessoas que direta ou indiretamente acompanham os serviços de execução. A adoção da transparência no processo de impermeabilização poderia contribuir para a identificação desses erros. São exemplos de práticas de transparência iniciar a execução com a exposição de desenhos nos locais da obra ou quadros com os sistemas definidos em projeto e de expor os quantitativos de material a ser utilizados naqueles locais e os procedimentos de execução.

Com essa prática da transparência, a fiscalização dos serviços de execução seria facilitada para as pessoas responsáveis por essa atividade, além de possibilitar que outras pessoas que não fizessem parte desse controle, mas que estivessem envolvidas na execução de alguma atividade adjacente ao serviço de impermeabilização, pudessem acompanhar esse serviço.

\section{Ineficiência nos processos provocada pelo desperdício}

Ao analisar o processo integrado da impermeabilização sob o aspecto dos desperdícios elencados por Ohno (1997), foi possível identificar as principais perdas em cada um dos processos, sinalizando, assim, as oportunidades de melhoria.

No processo de projeto, o desperdício do tempo de espera no recebimento de informações para o andamento do projeto de impermeabilização acarreta um tempo maior para execução desse projeto.

Como já foi comentado, existem muitas mudanças nos demais projetos da obra que interferem na impermeabilização e que necessitam ser consideradas. Sendo assim, o uso de projetos obsoletos, durante a elaboração do projeto de impermeabilização, contribui para a definição de metragens de áreas de impermeabilização erradas, gerando erro no quantitativo de materiais e, consequentemente, desperdício devido a compras desnecessárias ou insuficientes.

Essa compra de material a mais que o necessário no processo de aquisição se deve a uma informação errada, gerada durante o processo de projeto, como foi apresentado nos resultados. Quando o projeto de impermeabilização gera a informação da quantidade de material menor que a necessária, um serviço pode ser paralisado, por falta de material, com consequente atraso nos serviços.

A grande movimentação dos materiais em função do armazenamento deles em locais distantes do local de aplicação pode gerar perdas devido a avarias ocorridas no trajeto, além da perda de tempo na movimentação quando as distâncias percorridas são grandes.

Quando uma construtora compra todo o material, ou grande parte dele, sem que haja uso imediata, gera outro tipo de desperdício, na forma de estoque desnecessário. A falta de cuidados com esse estoque pode provocar perdas devido a danos nas embalagens e, até mesmo, vencimento do prazo de uso dos produtos.

A maior quantidade de fontes de desperdícios na impermeabilização ocorre no processo de execução. A frequência de operários parados aguardando a chegada de material ao local de trabalho, ou esperando liberação das áreas pela construtora, devido a serviços que antecedem a impermeabilização ainda estarem pendentes, é um desperdício na forma de tempo que leva a atraso nos serviços de impermeabilização, possivelmente acarretando custos adicionais à obra. A espera por 
liberação de área reflete uma possível falta de planejamento do sequenciamento das etapas construtivas que antecedem a instalação da impermeabilização.

Outra fonte de desperdício observada foi o retrabalho de serviços realizados. Esse retrabalho está intimamente relacionado ao uso de práticas não recomendadas pelas normas e procedimentos, refletindo em danos prematuros aos sistemas instalados. Isso poderia ser minimizado caso a empresa contratante da impermeabilização tivesse melhor conhecimento sobre esse serviço para o acompanhamento e fiscalização. Além do uso de práticas não recomendadas, o retrabalho se deve também ao fato de que é comum a execução da impermeabilização em áreas que ainda não estão preparadas para receber esse procedimento. Como isso, a impermeabilização é constantemente danificada, propositadamente, para a conclusão de tarefas de outros sistemas da obra que deveriam estar acabados para dar início à impermeabilização.

Muitos erros cometidos que foram evidenciados nas visitas são considerados básicos para uma empresa especializada em serviço de impermeabilização. Isso mostra uma deficiência no treinamento de seus operários, cujos erros se tornam mais frequentes em função da ausência de inspeção para identificação de não conformidades.

\section{Atendimento às normas e procedimentos dos sistemas de impermeabilização}

Os resultados da avaliação dos critérios definidos para o constructo conformidade mostram que os processos de projetos e aquisição da impermeabilização estão de acordo com as boas práticas esperadas, ou seja, os projetos procuram seguir as orientações e prescrições da norma, e as aquisições dos materiais são feitas conforme orientam os projetos.

No entanto, ainda é pouco usual a execução de um projeto de impermeabilização nas obras. Quando isso acontece, é possível a ocorrência de erro na seleção e escolha dos sistemas de impermeabilização pela construtora, em virtude da deficiência na análise mais detalhada da obra, suas particularidades e interfaces com outros sistemas.

Os resultados apresentados em relação à conformidade no processo de execução comprovam que as empresas e obras visitadas ainda executam atividades em desacordo às exigências das normas relacionadas à impermeabilização e aos procedimentos de aplicação dos materiais previstos pelos fabricantes.
Isso é reflexo do despreparo dos profissionais, conforme evidenciado nas entrevistas e visitas.

Nessas condições, o resultado gerado pelo serviço de aplicação dos sistemas de impermeabilização é comprometido, podendo produzir sistemas que não desempenhem satisfatoriamente a função de promover a proteção e a estanqueidade das estruturas.

\section{Recomendações para a melhorias}

A partir dos resultados e suas discussões apresentadas, foram propostas melhorias para a gestão do processo integrado de projeto, aquisição e execução de sistemas de impermeabilização, destacando a importância de tratar esse sistema de forma integrada, conforme descrito a seguir.

(a) ratifica-se a necessidade de contratação de um projeto de impermeabilização, e não apenas uma especificação, com o objetivo de garantir um sistema de impermeabilização mais eficiente e garantia de maior durabilidade;

(b) recomenda-se que os demais projetos de uma obra (estrutural, instalações, revestimento e paisagismo) sejam elaborados considerando suas interfaces com a impermeabilização, de forma a reduzir as dificuldades de instalação deste sistema, bem como considerar suas necessidades;

(c) é importante que o projeto de impermeabilização facilite a gestão de compras e controle dos materiais na obra, por meio de um quadro-resumo, contendo os sistemas e a quantidade de materiais utilizados em cada local de aplicação, de forma transparente, para auxiliar no controle visual;

(d) sugere-se que o processo executivo da impermeabilização seja fiscalizado por profissional capacitado, utilizando-se ferramentas de verificação de conformidade em relação a padrões normativos e recomendações práticas;

(e) recomenda-se a realização de treinamento sobre o projeto e sobre os procedimentos de execução tanto para a empresa responsável pela execução dos serviços como para os técnicos das construtoras que irão participar do processo de aquisição e acompanhamento da execução. As oportunidades de melhoria no projeto deverão ser discutidas na presença do projetista;

(f) sugere-se que a aquisição dos materiais aconteça em um período próximo a sua utilização, para evitar avarias no armazenamento e perdas devido à movimentação interna; $\mathrm{e}$ 
(g) por fim, é importante que as construtoras e as empresas contratadas para a aplicação da impermeabilização criem um cronograma de execução da impermeabilização, de forma a facilitar o controle da disponibilidade e o fluxo de materiais na obra.

\section{Conclusões}

O presente artigo propôs um estudo sobre a gestão do sistema de impermeabilização de forma integrada, analisando-se a inter-relação dos três principais intervenientes responsáveis pelos processos de projeto, aquisição de materiais e execução dos serviços de impermeabilização.

A primeira contribuição deste trabalho é a proposição de uma estrutura capaz de sistematizar o processo de identificação de problemas do sistema de impermeabilização de forma integrada, incluindo projeto, aquisição de materiais e execução, e levando em consideração aspectos de fluxo das informações, desperdícios e conformidade em relação aos padrões normativos.

A segunda contribuição é a avaliação do processo integrado de impermeabilização. Nos processos de projeto e aquisição observou-se que os maiores problemas estão relacionados ao fluxo das informações e ao desperdício, e que a conformidade em relação às normas está sendo cumprida. Na aplicação do sistema de impermeabilização, foram evidenciados problemas para os três constructos analisados, apontando que a execução do sistema é um processo crítico que merece atenção especial.

Foi possível também identificar diversas oportunidades de melhorias, de acordo com os critérios de avaliação definidos para análise, entre os quais se destacam:

(a) ratificação da necessidade de elaboração de projeto de impermeabilização para as obras;

(b) compatibilização entre os projetos da obra, tais como estrutura, instalações, revestimentos e paisagismos e o projeto de impermeabilização, evitando problemas como consumo excessivo de materiais, adoção de soluções equivocadas durante a execução da obra, custos não previstos e comprometimento da durabilidade dos sistemas;

(c) planejamento das etapas da obra que possuam interface com a impermeabilização, promovendo maior transparência e evitando problemas como negligência de etapas e procedimentos durante a execução, o que compromete a qualidade final do serviço, liberação de áreas com pendências de outros serviços que antecedem a impermeabilização e descumprimento a procedimentos previstos para o bom desempenho dos sistemas de impermeabilização;

(d) melhoria no controle de desperdícios - a maior fonte de desperdícios nos três processos em estudo refere-se à espera por informações, por liberação de áreas, por aprovação de compras e por disponibilidade de materiais no local de trabalho, configurando-se em etapas que não agregam valor e, portanto, que reduzem a produtividade nos processos; e

(e) aumento do nível de conhecimento dos engenheiros e técnicos sobre os serviços de impermeabilização e de sua importância para a proteção das construções.

Por fim, com base nos problemas e oportunidades de melhorias, foram apresentadas recomendações para os gestores de obra, destacando as necessidades prementes para garantir um processo integrado de gestão no processo de projeto, aquisição e execução de sistemas de impermeabilização. As análises e recomendações propostas devem permitir que o setor da construção civil promova a aplicação mais adequada dos recursos envolvidos para proteção das partes construtivas, por meio da impermeabilização, contribuindo para a melhoria da qualidade e a consequente maior vida útil das construções.

\section{Referências}

ASSOCIAÇÃO BRASILEIRA DE NORMAS TÉCNICAS. NBR 9574: xecução de impermeabilização. Rio de Janeiro, 2008. 14 p.

ASSOCIAÇÃO BRASILEIRA DE NORMAS TÉCNICAS. NBR 9575: impermeabilização: seleção e projeto. Rio de Janeiro, 2003. 12 p.

\section{CODINHOTO, R. Diretrizes Para o}

Planejamento e Controle Integrado dos Processo de Projeto e Produção na Construção Civil. Porto Alegre, 2003. Dissertação (Mestrado em Engenharia Civil) - Programa de PósGraduação em Engenharia Civil, Universidade Federal do Rio Grande do Sul, Porto Alegre, 2003.

COLOMBO, C. R.; BAZZO, W. A. Desperdício na Construção Civil e a Questão Habitacional: um enfoque CTS. 2001. Disponível em: <http://www.oei.es/salactsi/colombobazzo.htm>. Acesso em: 10 ago. 2011.

\section{CONSELHO REGIONAL DE ENGENHARIA, ARQUITETURA E AGRONOMIA DE PERNAMBUCO. Pesquisa Sobre Impermeabilização nas Edificações Residenciais Condominiais da Cidade do Recife. Recife: CREA-PE, 1997. Relatório.}


EASTERBY-SMITH, M.; THORPE, R.; LOWE, A. Management Research: an introduction. Londres: Sage, 1991.

FABRÍCIO, M. M. Projeto Simultâneo na Construção de Edifícios. São Paulo, 2002. Tese (Doutorado em Engenharia Civil) - Escola Politécnica, Universidade de São Paulo, São Paulo, 2002.

FIREMAN, M. C. T.; FORMOSO, C. T.; ISATTO, E. L. Integrating Production and Quality Control: monitoring making-do and unfinished work. In: ANNUAL CONFERENCE OF INTERNATIONAL GROUP OF LEAN CONSTRUCTION, 21., Fortaleza, 2013. Proceedings... Fortaleza, 2013.

FONTANINI, P. S. P.; PICCHI, F. A. Mentalidade Enxuta na Cadeia de Fornecedores da Construção Civil: aplicação de macromapeamento. In: SIMPÓSIO BRASILEIRO DE GESTÃO E ECONOMIA DA PRODUÇÃO, 3., São Carlos, SP, 2003. Anais... São Carlos, 2003.

FORMOSO, C. T. et al. Material Waste in Building Industry: main causes and prevention. Journal of Construction Engineering and Management, Virginia, v. 128, n. 4, p. 316-325, 2002.

GODÓY, E. H. P.; BARROS, M. B. A Avaliação de Desempenho dos Sistemas de Impermeabilização Com Argamassa Polimérica. In: SIMPÓSIO BRASILEIRO DE IMPERMEABILIZAÇÃO, 10., São Paulo, 1997. Anais... São Paulo, 1997.

HWANG, B. et al. Measuring the Impact of Rework on Construction Cost Performance. Journal of Construction Engineering and Management, Virginia, v. 135, n. 3, p. 187-198, 2009.

ISATTO, E. L. et al. Lean Construction: diretrizes e ferramentas para o controle de perdas na construção civil. Porto Alegre: SEBRAE-RS, 2000 .

IOSHIMOTO, E. Incidência de Manifestações Patológicas em Edificações Habitacionais. In: EPUSP, 1988, São Paulo. Anais... São Paulo: USP, 1988.

ISCHAKEWITSCH, G. T. Dimensionamento, Gerenciamento de Risco, Inspeção e Investigação. In: SIMPÓSIO BRASILEIRO DE IMPERMEABILIZAÇÃO, 10., São Paulo, 2013. Anais... São Paulo, 2013.
KOSKELA, L. Application of the New Production Philosophy to Construction. Stanford, CA: Center for Integrated Facility Engineering, Stanford University, 1992. (Technical Report, n. 72).

KOSKELA, L. Making-do: the eight category of waste. In: ANNUAL CONFERENCE OF INTERNATIONAL GROUP OF LEAN CONSTRUCTION, 12., 2004, Elsinor, Denmark. Proceedings... Elsinor, Denmark, 2004.

KOSKELA, L. HUOVILA, P. On Foundations of Concurrent Engineering. In: INTERNATIONAL CONFERENCE ON CONCURRENT ENGINEERING IN CONSTRUCTION, London, 1997. Proceedings... London: The Institutional of Structural Engineers, 1997.

LIMA, J. L. A. Processo Integrado de Projeto, Aquisição e Execução de Sistemas de Impermeabilização em Edifícios Residenciais: diagnóstico e proposição de melhorias de gestão. Salvador, 2012. Dissertação (Mestrado Profissional em Gestão e Tecnologia Industrial) Programa de Pós-Graduação em Gestão e Tecnologia Industrial, Faculdade Cimatec, Salvador, 2012.

LOVE, P.; LI, H. Quantifying the Causes and Costs of Rework in Construction. Construction Management and Economic Reading, v. 18, n. 4, p. 479-490, 2000.

MARTINS, G. A.; PELISSARO, J. Sobre Conceitos, Definições e Constructos nas Ciências Contábeis. Base - Revista de Administração e Contabilidade da Unisinos, v. 2, n. 2, p. 78-84, 2005.

MORAES, C. R. K. Impermeabilização em Lajes de Cobertura: levantamento dos principais fatores envolvidos na ocorrência de problemas na cidade de Porto Alegre. Porto Alegre, 2002. Dissertação (Mestrado em Engenharia Civil) Programa de Pós-Graduação em Engenharia Civil, Universidade Federal do Rio Grande do Sul, Porto Alegre, 2002.

OHNO, T. O Sistema Toyota de Produção: além da produção em larga escala. Porto Alegre: Artes Médicas, 1997.

PERALTA, A. C. Um Modelo do Processo de Projeto de Edificações, Baseada na Engenharia Simultânea, em Empresas Construtoras Incorporadoras de Pequeno Porte.

Florianópolis, 2002. 139 f. Dissertação (Mestrado em Engenharia de Produção) - Programa de Pósgraduação em Engenharia de Produção, UFSC. Florianópolis, 2002. 
PORCELLO, E. C. Impermeabilização. Porto Alegre: PUCRS, 1998.

ROCHA, F. E. M. Planejamento lean. Téchne, n. 151 , p. 20-23, 2009.

SCHLAEPFER, C. B. R.; CUNHA, R. Impermeabilização e Recuperação Estrutural. Rio de Janeiro, Sika do Brasil, 2001.

SORTINO, G. Guia do Executivo Para Tomada de Decisões: CEO's tool box. São Paulo: Atlas, 2005.

SOUZA, R.; BAÍA, J. L.; GUNJI, H. Sistema de Gestão Para Empresas de Incorporação

Imobiliária. São Paulo: O Nome da Rosa, 2004.
SOUZA, J. C. S.; MELHADO, S. B. Parâmetros Para Seleção e Projeto de Impermeabilização de Pisos do Pavimento tipo de Edifícios. In: ENCONTRO NACIONAL DE ENGENHARIA DE PRODUÇÃO, 27., Foz do Iguaçu, 1997. Anais... Foz do Iguaçu: ANTAC, 1997.

VIANA, D. D.; FORMOSO, C. F.; KALSAAS, B. T. Waste in Construction: a systematic literature review on empirical studies. In: ANNUAL CONFERENCE OF INTERNATIONAL GROUP OF LEAN CONSTRUCTION, 20., San Diego, 2012. Proceedings... San Diego: State University of San Diego, 2012.

YAZIGI, W. A Técnica de Edificar. 10. ed. São Paulo. Pini; Sinduscon, 2009.

YIN, R. K. Estudo de Caso: planejamento e métodos. 2. ed. Porto Alegre: Bookman, 2001.

Jorge Luiz de Aquino Lima

Faculdade de Tecnologia Senai/Viapol | Av. Orlando Gomes, 1845, Piatã | Salvador - BA - Brasil | CEP 41650-010 | Tel.: (71) 3462-9500 | E-mail: jorgelima@viapol.com.br

Francisco Uchoa Passos

Faculdade de Tecnologia Senai/Cimatec | E-mail: francisco.uchoa@fieb.org.br

Dayana Bastos Costa

Departamento de Construção e Estruturas, Escola Politécnica | Universidade Federal da Bahia | Av. Aristides Novis, 2, Federação | Salvador - BA - Brasil | CEP 40210-630 | Tel.: (71) 3283-9731 | E-mail: dayanabcosta@ufba.br

Revista Ambiente Construído

Associação Nacional de Tecnologia do Ambiente Construído

Av. Osvaldo Aranha, $99-3^{\circ}$ andar, Centro

Porto Alegre - RS - Brasil CEP $90035-190$

Telefone: +55 (51) 3308-4084

Fax: +55 (51) 3308-4054

www.seer.ufrgs.br/ambienteconstruido

E-mail: ambienteconstruido@ufrgs.br 